Article

\title{
Toward Sustainable Energy-Independent Buildings Using Internet of Things
}

\author{
Naser Hossein Motlagh ${ }^{1, *(D)}$, Ali Khatibi ${ }^{2}\left(\mathbb{D}\right.$ and Alireza Aslani ${ }^{2}$ (I) \\ 1 Department of Computer Science, University of Helsinki, FI-00014 Helsinki, Finland \\ 2 Department of Renewable Energy and Environment, University of Tehran, Tehran 14174-66191, Iran; \\ alikhatibi83@ut.ac.ir (A.K.); alireza.aslani@ut.ac.ir (A.A.) \\ * Correspondence: naser.motlagh@helsinki.fi
}

Received: 10 October 2020; Accepted: 12 November 2020; Published: 15 November 2020

\begin{abstract}
Buildings are one of the primary consumers of energy. In addition to the electricity grids, renewable energies can be used to supply the energy demand of buildings. Intelligent systems such as the Internet of Things (IoT) and wireless sensor technologies can also be applied to manage the energy consumption in buildings. Fortunately, integrating renewable energies with these intelligent systems enables creating nearly zero-energy buildings. In this paper, we present the results of our experimentation to demonstrate forming such a building and showing the benefits for building users and the society. We create a system by integrating photovoltaic (PV) technology with an IoT-based control mechanism to supply and consume energy. We further illustrate "how the integration of IoT and PV technology can bring added value to the users?". To this end, we evaluate the performance of our system against conventional ways of energy supply and consumption for a lighting use case in a dairy store. We also investigate the environmental and economic impacts of our system. In our implementation, for the IoT-based control system, we have used a set of sensors, a server, and a wireless network to control the energy consumption. We developed a web application for user interaction and software-based settings. To control the lighting system, we developed an algorithm that utilizes the ambient light, users' movements inside the store and a historical dataset. The historical dataset was collected from the users' behaviour as a training set for the algorithm for turning on and off the lights. We also designed an electricity management system that computes the energy generation by the PV panels, controls the energy supply, and imports and exports electricity to the grid. The results show that our system is an efficient approach for creating energy-independent buildings by integrating renewable energies with IoT-based control systems. The results also show that our system not only responds to the internal demand by using domestic supply, but it also (i) offers economic benefit by exporting extra renewable electricity to the grid, and (ii) prevents producing huge amounts of $\mathrm{CO}_{2}$. Our system is one of the first works to achieve a nearly zero-energy building in the developing countries with low electricity accessibility.
\end{abstract}

Keywords: intelligent system; internet of things; smart homes; building energy management; nearly zero-energy buildings; solar systems; photovoltaic panel

\section{Introduction}

Buildings are the main sources of electricity consumption in different countries. In developed countries, the amount of electricity consumption in buildings is approximately $40 \%$ of the total electricity consumption per year [1]. Globally, the AC and lighting systems are the main sources of electricity consumption in buildings which consume nearly $40 \%$ and $20 \%$ of total electricity, respectively [2]. In response to the climate change, it is expected that the use of AC will increase by 10 times by 2050 [3]. Electricity consumption for lighting systems is also expected to increase by 
$80 \%$ by 2030 [4]. This necessitates development of policies for increasing the share of renewable energy supply in final energy consumption [5]. The growing demand for electricity forces the industries and research communities to find solutions for optimizing the electricity consumption in buildings [6]. In addition, the increasing cost of energy has led many efforts to employ smart energy management systems which are smart ways for monitoring, controlling, and saving energy in smart homes $[7,8]$. Hence, different approaches have been considered to minimize the electricity consumption while ensuring the users' needs and comforts. The examples include improving designs for future buildings, optimizing dimensions of lighting windows, using thermal insulation materials in walls, developing green spaces in perimeter of buildings, and production of low-power consumption appliances [9].

Other approaches use Internet of Things (IoT) which is both intelligent and cyber-enabled energy management system for buildings [10]. Actually, IoT can transform energy systems by providing a sustainable solution to meet the growing demands of access to affordable, clean, and sustainable energy [11]. The intelligent approaches aim to improve energy efficiency and transform the buildings into nearly zero energy buildings [12]. The nearly zero energy buildings have very high energy performance and the low energy requirement of these buildings mostly supplied from renewable energies, including energies produced on-site or near the buildings [13]. The IoT-based approaches utilize sensor networks and smart metering to enable intelligent systems to monitor [14] and control the energy consumption in the buildings [15], while meeting the visual and thermal comfort for the users [16]. IoT also can be used for anomaly detection in smart home operation from users' behaviors and home conditions, allowing faulty home appliance detection and replacement $[17,18]$. These works develop software-based electricity consumption to maximize the occupants' comfort [19] or they use web-based interactive frameworks of visualizing and authoring IoT in indoor environments [20]. In these approaches, the IoT system includes wireless sensor networks and employs automatic control of the appliances [21]. They use a computational system which operates through a set of predefined rules used to control a set of sensors and switches, connected to home appliances [22].

Some research perform decision-making systems that take into account the real-time electricity cost [23]. Other works use computational intelligence considering occupant's behavior [24,25], and utilizing context-based approaches using IoT structures and by collecting data from objects, humans, and services [26], and considering the user perceptions and habits for controlling electricity consumption [27]. The benefit of using IoT in buildings beneath to fully control the buildings connected system or appliance and decreasing the investment and maintenance costs of the buildings $[28,29]$. Furthermore, IoT allows for quantifying the energy consumption of home automation systems [30,31], and enabling improving the energy efficiency of households through clustered energy storage system [32]. Moreover, the advances on utilizing renewable energies have provided the use of Photovoltaic systems for various use cases including the buildings [33]. Employing Photovoltaic systems to generate electricity in countries which receive high levels of daily sunlight is an effective approach. However, large deployment and usage of this technology, mainly in developing countries, will still take a long time. However, the countries in the middle east, central and north Africa and central America would be the best places to largely use the solar sources to generate the electricity [5,34].

The existing studies in literature only focus on developing intelligent approaches or they only propose or implement solar systems to improve the energy consumption in buildings. To the best of the author's knowledge, a study that integrates the electricity generation using the PV panels with an IoT system to generate electricity and control the consumption while taking into account the users' habits and comforts and offers economic benefits all in one place does not exist in the literature. Our system is also one of the first studies to achieve a nearly zero-energy building in the developing countries with low electricity accessibility. The concept of our approach which is also illustrated in Figure 1 enables the buildings to independently generate, control, and consume the electricity in an environmentally friendly way. 
Furthermore, despite different studies performed in the fields of renewable energy systems and the Internet of things (IoT), most of them have a complex language that cannot convince the end-users to use these technologies in practice. Indeed, in a simple way, our research demonstrates how businesses and households can integrate the IoT with sustainable energy technologies to achieve multiple benefits. Particularly, our research is suitable for developing countries with low electricity accessibility, and the countries with solar radiation higher than average.

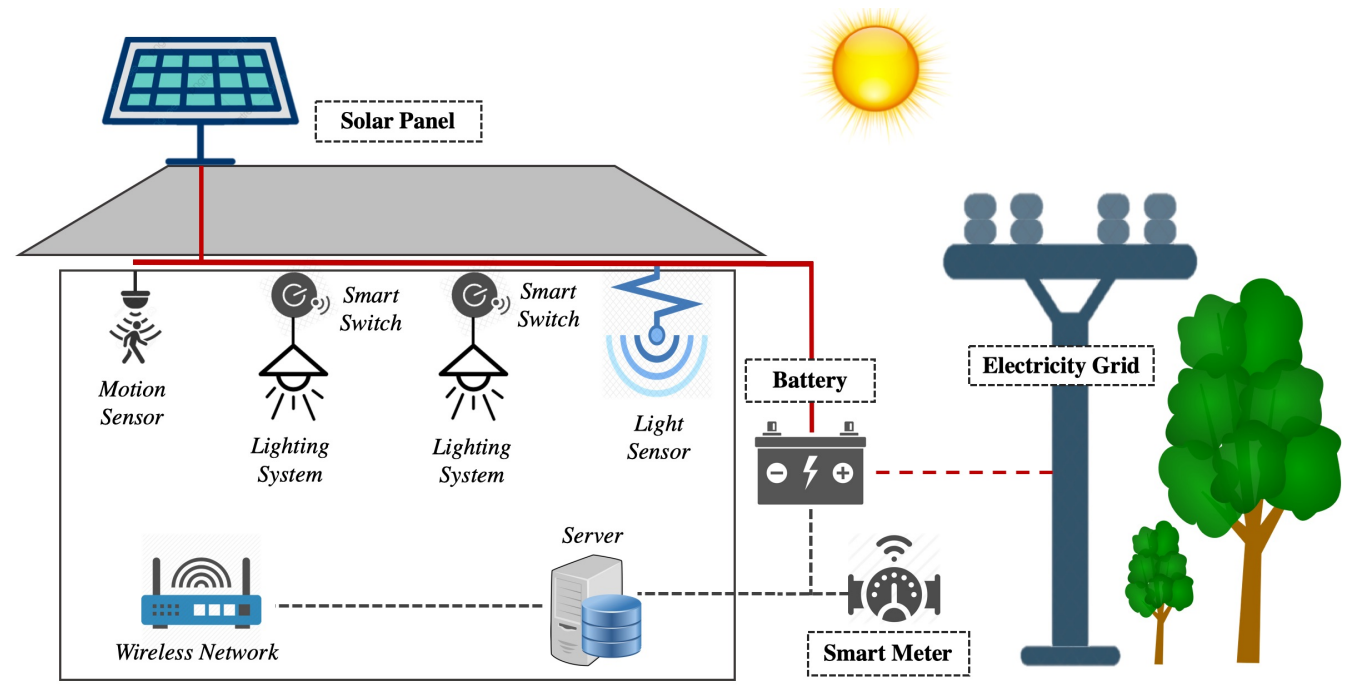

Figure 1. The concept of IoT-enabled building energy management system.

As our methodology, we implemented and carried out an experimentation for three months by adding a PV panel to a building roof to generate solar energy. We designed an electricity management system that controls the electricity generation and consumption and receives electricity or sends the extra generated electricity to city the grid.

We also implemented an IoT system that controls the end user device electricity consumption, where in our case we control the lighting systems of a store. The IoT system is based on two light sensors to sense the ambient daylight, a server (as a database and control center), a Raspberry Pi which is used as the system gateway, a motion detector to track the movements, a Wi-Fi network, and a dataset collected from the users' habits. We also developed a web application to ease the user interaction with the system and offer software-based settings.

To enable the control system to operate, we designed an algorithm that senses the ambient daylight to control the electricity consumption while ensuring the visual comfort; and integrates the users' habit data on using the place while updating the users' presence through motion sensing. For the users' habit, we collected two months of historical data from the users' movement in April and May 2019, where we used this data as a training set in our algorithm for turning on and off the lights when there are no users in the place. During these two months, the user was allowed to turn on and off the lamp using the software user interface at his desired times. In June 2019, we tested the IoT system using the historical without user's input and we collected the data from the system performance.

As a result, we evaluate the performance of our system against a conventional way of energy supply and consumption. We also demonstrate the economic benefits of implementing PV panels for electricity generation in real life; and we highlight the impact on the environment by stopping $\mathrm{CO}_{2}$ production. Our results show that using five PV panels with small sizes as $25 \times 355 \times 510 \mathrm{~mm}$ is not only sufficient to provide the electricity demand of a lighting use case, but the extra generated electricity can be exported to the grid which offers revenues for the user. In nutshell, our IoT system offers multiple benefits for businesses and households, and enables energy-independent and nearly zero energy buildings particularly in the regions with low electricity accessibility and the places where solar radiation is higher than average. 
This paper is organized in the following fashion. Section 2 presents the system model. Section 3 explains the control systems. Section 4 presents the results of our experiment. In Section 5, we provide a discussion and finally we conclude the paper in Section 6.

\section{The System Model}

Figure 1 describes the concept of solar-based energy generation and IoT-enabled intelligent controlled electricity consumption in a building. In this concept, sensors and switches of the appliances individually (lighting system in our study) are connected to a server through a wireless network. The connections can be any type of reliable short-range wireless technology or even an Ethernet cable. In addition, the data storage and the functions and electricity control mechanisms are performed on the server.

\subsection{System Design}

Our system consists of two parts: (i) photovoltaic solar panels, (ii) a laptop which is used as server, and (iii) IoT-based control system which includes a light sensor, a motion detector, i.e., Passive Infrared (PIR) sensor, two LED lights with the switches, a Raspberry Pi (RPi) (the central connection of different devices), and a network router which is connected to the Internet and offers wireless connection.

\subsubsection{Photovoltaic Solar Panels}

We used five photovoltaic panels of model "Zytech ZT20-18-P", with $25 \times 355 \times 510 \mathrm{~mm}$ dimensions generating an output power of 20 watt with $12 V D C \& 1.1 \mathrm{~A}$. These panels are used to transform the sunlight received at their panels to $D C$ voltage and supply the electricity demand in the building.

\subsubsection{IoT-Based System}

We used a Raspberry Pi (RPi) Zero WH which holds built-in Ethernet and Wi-Fi network connections. RPi is used as the gateway of the system to connect the sensor and motion detector as well as the switches of the LEDs to the laptop which works as the server. We used a Yocto-Light-V3 that is a USB ambient light sensor and can simply be connected to the RPi board from the USB port. In addition, the switches of the LED lights were also connected to RPi using Ethernet cables. Indeed, to operate the system, we developed the required software for activating the light sensor, motion detector, and the switches using Python programming language and stored on a memory card and inserted in RPi. We provided the electricity using RPi's power supply. In the systems, all of the elements obtained a static IP address and we used the TCP/IP protocol to establish the communications.

In the designed system, while the light sensors measure the ambient light, motion detector captures the movement and the switches obtain the status of the LED lights. Indeed, motion detectors not only are increasingly being deployed into smart environments, e.g., to control lighting and ventilation for energy management purposes, but also they have been used as a proxy for indoor air quality estimation [35]. In our design, we use one motion detector to control the lighting system based on the presence of the place users. In addition, to provide security for the system, we used security keys, encryption, and decryption modules using Python. Therefore, to provide security for the system, we used security keys, encryption, and decryption modules using Python.

Indeed, the measured status of the sensors is encrypted applying a unique security key that is defined by the system administrator, i.e., the user. The security key is stored on the server and also configured at the corresponding sensor device or switch. The security configuration is designed so that any measured data by the sensors requires two rounds of encryptions: (i) the security key encryption, and (ii) data encapsulation due to using TCP/IP protocol. Therefore, any transmitted data between the server and sensors or switches is encrypted and decrypted using its particular security key.

In nutshell, the sensors and the switches in the system use the scheme shown in Figure 2 to communicate. As illustrated, the sensors' communications are unidirectional and the data 
transmission happens at the sensors. Meanwhile, the communications of the switches are bi-directional, meaning that the switches can send and receive their status data to the server. If they receive data from the server, they are commanded to turn on or off the LED lights, which is due to avoiding electricity consumption and this then results in saving.

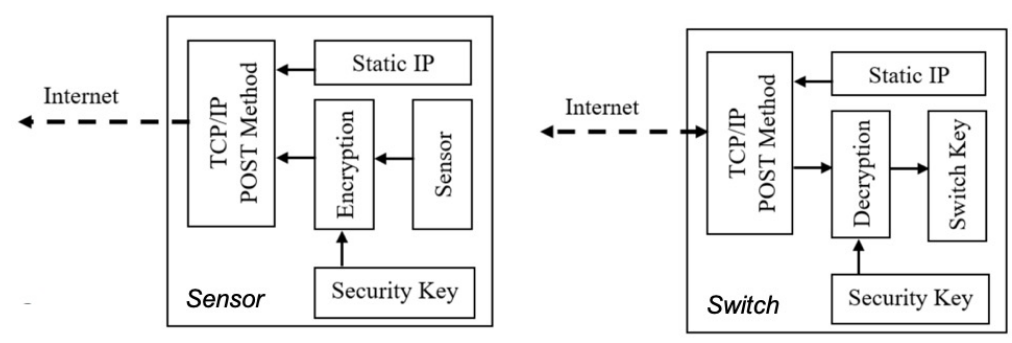

Figure 2. The scheme of sensors and switches.

\subsubsection{The Server}

To run the IoT-based control system, we used a laptop as a local server with the specifications presented in Table 1. Using a local server instead of an Internet server was to prevent the building's control systems from failing when the Internet connection is down for any technical problem. Hence, having a local server in smart homes secures their continuous operations and ensures a reliable system. We developed a web application (Figures 3 and 4), which is stored on the laptop with a configuration presented in Table 1.

Table 1. The configuration of the server.

\begin{tabular}{cc}
\hline Property & Description \\
\hline Laptop Model & Lenovo Ideapad 330-F \\
OS & Linux CentOS 7.5 \\
Hard Drive & HDD 1 TB 5400 RPM \\
CPU & Intel Celeron 3867U 2.0 GHz \\
RAM & 4 GB \\
Web Server & APACHE 2.4.34 \\
IP & Local \\
\hline
\end{tabular}

\subsection{Web Application}

In the back-end, to execute the control system, we used PHP programming and MySQL to develop a Web application consisting (i) Graphical User Interface (GUI) and (ii) Web API.

(i) The GUI which is designed to report the instant status of the building (in our case, the LED lights). The GUI is shown in Figure 3.

The GUI shows the electricity suppliers and consumers of the building and their respective status, updated at certain time intervals. The GUI has an administration section which is designed to allow the administrator of the system to modify the parameters and assign values (Figure 4 ). The administration section allows for modifying the user's information, user's habit, and cost of electricity from the grid. The designed administration section consists of different tabs (options), each one with specific functions and editable fields. For example, selecting the sensor option or appliance option allows for modifying their IP address, security keys, locations, status, units of measurement, e.g., lux for lighting, and their status. The controller option allows for defining the rules and conditions for the system-for example, the administrator can define the level of lighting needed at the indoor environment. These options are enabled by the editable fields placed inside them. For instance, the status field in a sensor tab refers to the on and off mode of the device allows the administrator to remotely control (enable and disable) the device. 
Buildings Energy Management System Home Reports Help About Logout

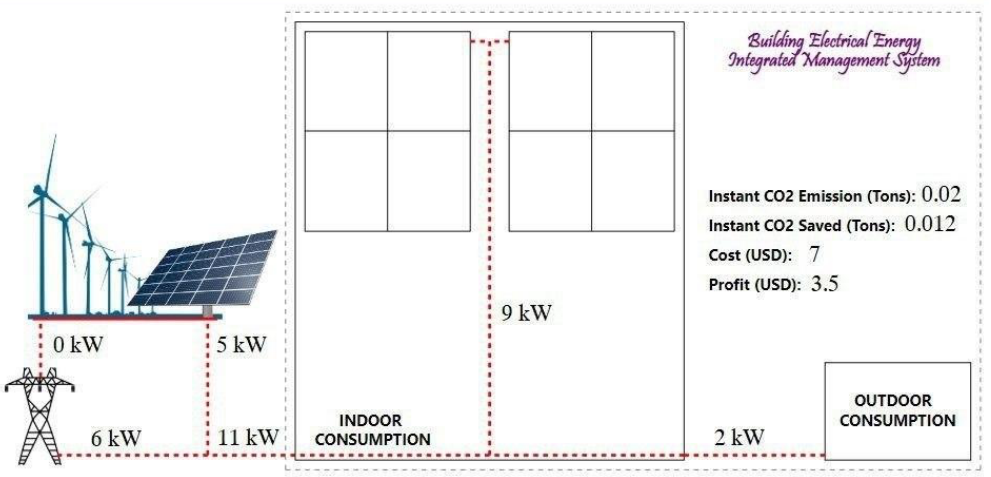

Figure 3. The homepage of GUI.

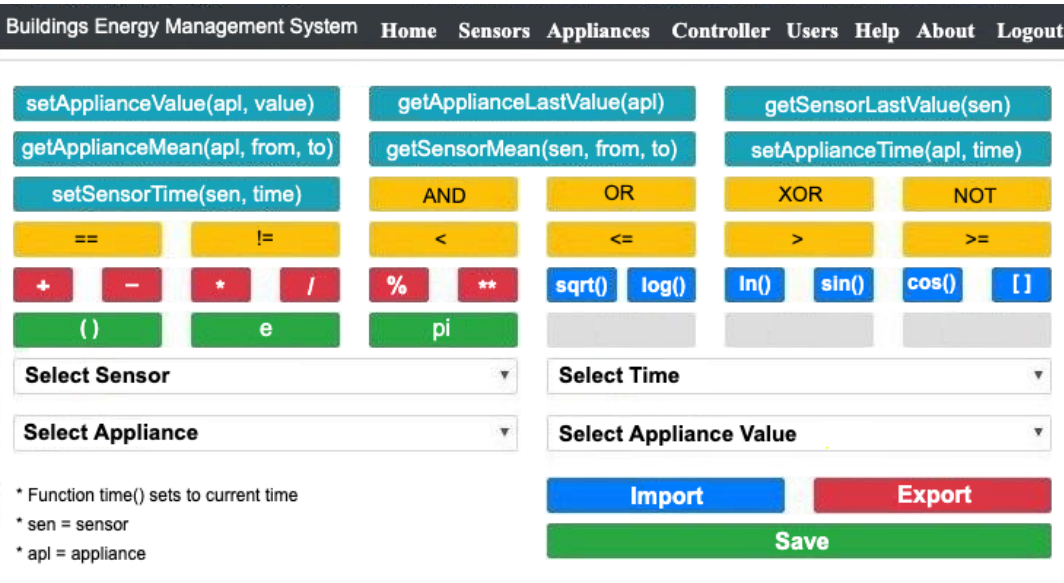

Figure 4. The administration section.

(ii) The Web API which works as a software gateway and connects to the sensors and switches. The Web API consists of a back-end program connected to the ports of the web server. The prototype of the control unit is illustrated in Figure 5. As depicted in this figure, the Web API receives all requests from the sensors and switches via the POST method of TCP/IP protocol. The requested and response data are also continuously stored in the database using the dedicated cryptographic algorithms. If the request comes from a switch, the kernel will be called and the data of related sensors and the previous status of the switch are also requested from the database. In addition, the new status of the switch will be determined and stored in the database. Then, the new status is sent to the relevant switch through the POST method. The Web API is designed so that, if there is no request from a switch for a long time or if a sensor shows an abnormal status, an alarm object, i.e., message will be sent to the administrator. Considering that the control unit uses the default setting specified by the administrator.

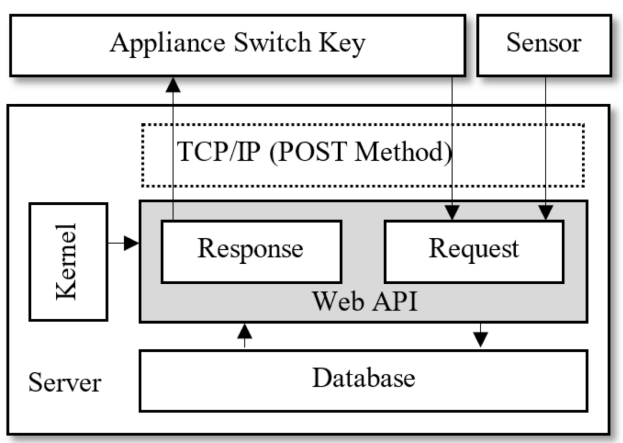

Figure 5. The Web API. 


\section{The Control Systems}

\subsection{Electricity Production and Consumption Management}

In this subsection, we explain the electricity management system for the lighting system. Because the electricity production with the panels, electricity consumption, and interaction with the grid requires a controlled plan, we planned a management system which is presented by a flowchart diagram in Figure 6.

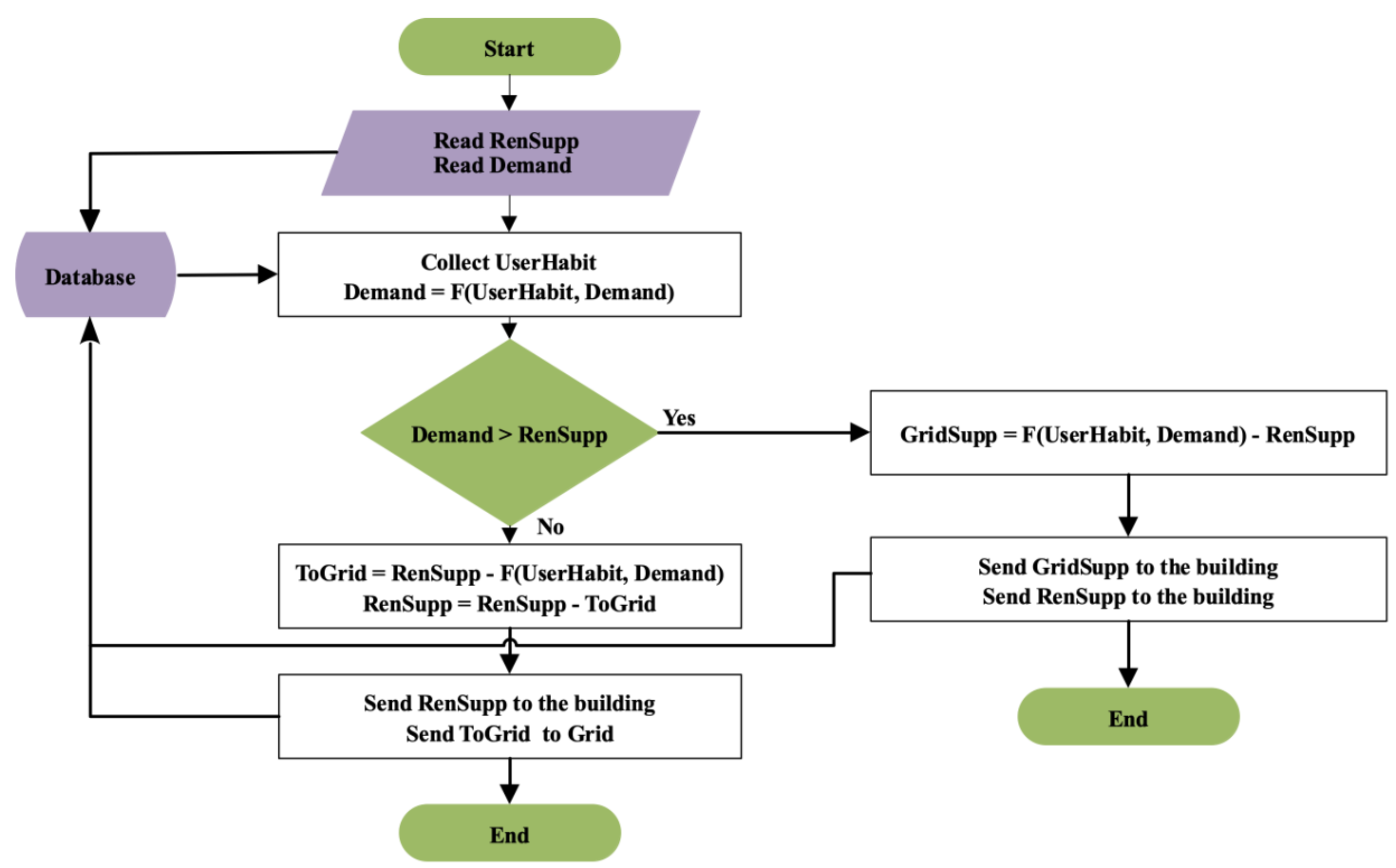

Figure 6. The electricity management system.

The logic of the electricity management system operates by reading the amounts of produced electricity by the solar panels $\left(E_{P}\right)$ and the building electricity consumption $\left(E_{C}\right)$ from their relevant sensors in real time. In the flowchart, RenSupp refers to the amount of generated electricity $\left(E_{P}\right)$ by the solar panels and Demand presents the real-time amount of electricity consumption $\left(E_{C}\right)$ in the building.

Next, the user habit $(\mathcal{H})$ is called from the database which includes the time-stamped historical values of all sensors. Then, the user habit $\mathcal{H}$ and and Demand, i.e., $E_{C}$, are inserted to a function called $F()$. In such a way, the amount of new demand is determined and replaced in the Demand variable, i.e., $E_{C}$ considering the historical data.

Next, the values of Demand $\left(E_{C}\right)$ and $\operatorname{RenSupp}\left(E_{P}\right)$ are compared by a conditional statement. If Demand $\left(E_{C}\right)$ is less than or equal to RenSupp $\left(E_{P}\right)$, it means that total demand of the building should supply from the renewable resources. Then, the surplus amount of generated electricity by the solar panels can be sold to the Grid. We denote this by $E_{T o G r i d}$ (shown by ToGrid in the flowchart). However, if RenSupp $\left(E_{P}\right)$ is less than Demand $\left(E_{C}\right)$, it means that generated electricity by the solar panels is not sufficient to meet the electricity demand of the building. Then, the remained amount of required electricity, i.e., GridSupp will be supplied by Grid $\left(E_{G}\right)$. In addition, all of the processes and operations of the management system are stored in the database.

Our system is designed so that the function $F()$ in the kernel of the web application can be defined in various ways. This flexibility of our system enables it to be a suitable mechanism for diverse settings in different buildings. In our study, we define the function $F()$ as average of Demand $\left(E_{C}\right)$ and the user habit $\mathcal{H}$. By determining the status of connected devices to the energy suppliers, the process ends. 
This process iterates periodically (e.g., each $30 \mathrm{~s}$ ) and then the status of sensors is stored in the database per iteration.

To manage the electricity production with the panels, electricity consumption, and interaction with the grid, let us recall the following relations. Generally, the total amount of electricity consumption in a building can be defined as:

$$
E_{N}=\sum_{i} P_{i} \cdot T_{i}
$$

where $P_{i}$ is the power of $i^{t h}$ appliance, $T_{i}$ is the usage time of the $i^{\text {th }}$ appliance, and $E_{N}$ is the total amount of required electricity. In our study, we consider the grid electricity $E_{G}$ and the electricity generated by the solar panels $E_{P}$ to supply the building demand. We define the summation of these two sources as accessible energy $E_{A}$ :

$$
\begin{gathered}
E_{A}=E_{P}+E_{G} \\
E_{P}=E_{\text {Demand }}+E_{\text {ToGrid }}
\end{gathered}
$$

where $E_{\text {Demand }}$ is the energy that supplies the building demand and $E_{\text {ToGrid }}$ refers to the energy which will be sent to the Grid if there is any. Note that any electricity from renewable resources will not be sent to Grid, if the building demand Demand is greater than the electricity from generated electricity $E_{P}$. Thus, using Equations (1) and (3), the energy management system will adjust the energy demand and consumption in the building.

\subsection{Lighting Control System}

In this subsection, we discuss the performance of our IoT enabled control system through implementation and experimentation in a dairy store (Figure 7) in the city of Tehran.
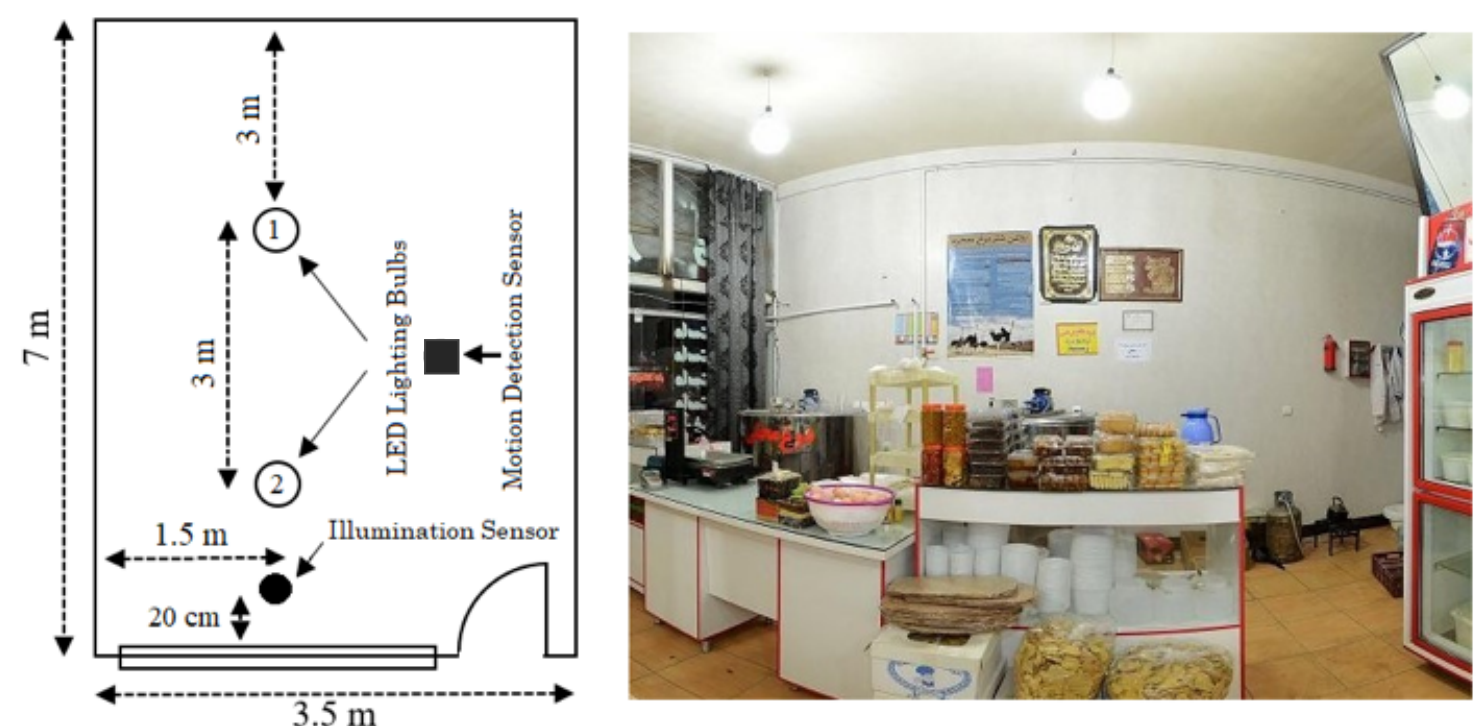

Figure 7. The plan and picture of the dairy store.

This city is located in the middle east with an elevation of $1178 \mathrm{~m}$ from the sea level. Tehran has semi-arid climate [36] with continental characteristics and Mediterranean climate prediction patterns. The weather conditions of the place of the experiment has a direct effect on the operations and performance of our energy management system, whereas the length of sunshine (in hours) is one of the main factors of electricity generation by PV. The average monthly daylight and minimum sunshine hours in Tehran are represented in Table 2 [37]. 
Table 2. The average of daylight and the minimum sunshine in hours (h) in Tehran for 2019 [37].

\begin{tabular}{ccccccccccccc}
\hline & Jan & Feb & Mar & Apr & May & Jun & Jul & Aug & Sep & Oct & Nov & Dec \\
\hline Daylight & 10.0 & 10.6 & 11.6 & 13.1 & 14.1 & 14.4 & 14.2 & 13.3 & 12.3 & 11.2 & 10.2 & 9.5 \\
Sunshine & 5.7 & 6.7 & 5.9 & 8.0 & 9.3 & 11.5 & 11.0 & 11.3 & 10.4 & 7.7 & 6.0 & 5.4 \\
\hline
\end{tabular}

The weather data shown in Table 2 illustrates that almost all of the months that have high average daylight also include a high average daily sunshine, whereas we carried out our experiments in April, May, and June which are among the months with highest average daily sunshine. Carrying out the experiment during these months with a high amount of sunshine enables the photovoltaic system to generate more electricity.

\subsubsection{Impact on Electricity Consumption}

To test the performance of the control system, we used the lighting system as the use case. Hence, we applied an illumination sensor and a power controller switch for the lighting system. Then, we added five photovoltaic panels to the roof of the building as power supplier.

We carried out the experiment by installing IoT-enabled devices in a dairy store in the center of Tehran. The picture and plan of the store are shown in Figure 7. As illustrated in this figure, we installed two LED lighting bulbs almost at the center of the store with a difference of $3 \mathrm{~m}$ in between them. We also installed an illumination sensor at $20 \mathrm{~cm}$ distance from the window of the store. We also installed a motion detector on the ceiling of the store to track the movements of people every $30 \mathrm{~s}$. As shown by the square shape on the plan of the store, the motion detector was placed between the two LEDs.

We connected both of the LED lighting systems, the illumination sensor and the motion detector to the IoT control system that controls the LEDs by turning them on and off. Then, we collected the data from the light sensor and status of the LEDs (if they are on or off) from the first of April to the end of June 2019. Our controlling system stored the total of 262,080 data points on the database during these months. We further stored the data in a MySQL database developed on the local server. In April and May 2019, our IoT-based control system only collected the data from sensors and the status of LEDs and stored them while allowing the user to modify the status of these LEDS during these two months. In this way, we collected the user habit data $(\mathcal{H})$ as explained in Figure 6.

The IoT-based control system works by the illuminance received at the sensor and implementing the Algorithm 1 on the RPi. To derive the Algorithm, we derive the parameters from our experiment and the service that is planned to be offered by the IoT-based control system. To derive the algorithm, we use inputs from the light sensor, real-time movement tracked by the motion detector, and collected historical data while aiming to offer an IoT-based service which is turning on and off the lights. In addition, the Algorithm considers the visual comfort levels defined for such an environment, i.e., dairy store which are assumed between 50 and 70 lux [38], and turns on and off the lighting bulbs using the illuminance received at the sensor.

In the Algorithm, $l x$ refers to the measured illumination (in lux); $l b 1$ and $l b 2$ denote to lighting bulbs LED1 and LED2 (as depicted in Figure 7). $l b x_{\text {stat }}$ refers to the status of the LEDs; and $l b x_{\text {pred }}$ denotes the prediction of LEDs status (i.e., $\mathrm{On}=1$, Off $=0$ ). The Algorithm uses the dataset stored on RPi. The dataset was collected from the user habit $\mathcal{H}$ for April and May 2019.

Figure 8 shows sample plots from the ambient light variations measured by the light sensor. Figure 8a illustrates the continuous measurement of light during June 2019 and Figure 8b shows one day of measurements on 1st June 2019. These results state that the light sensor has been operating constantly during the measurement time. The light sensor inside the store was not influenced by direct sunlight. This would be due to the fact the buildings in front of the store have prevented the solar irradiation from entering the store. Indeed, receiving direct solar irradiation (or by being at high temperatures) at the sensor would drift the sensor's measurement and degrade it leading to 
measurements performance and would require implementing calibration techniques [39]. From the measurements, it can be seen that the sensor has measured the ambient daylight received inside the store continuously. The measurements have correctly varied with the decrease and increase of daylight. This is obvious from measurements as shown in Figure 8. The maximum measured light intensity is at most $120 l x$ for all days. It is also obvious that the ambient daylight gradually increases from morning until the most lighter time (i.e., noon between 12:00 p.m. and 2:00 p.m.) (Figure 8b). The fluctuations that we observe in this figure, for example between 9:00 a.m. to 10:00 a.m., present possible cloudy times, or vehicles passing in the street or stopping in front of the building which limits the amount of ambient light to enter the store. In a nutshell, from the measurements, we can conclude that the sensor has been working properly and accurately without any failure.

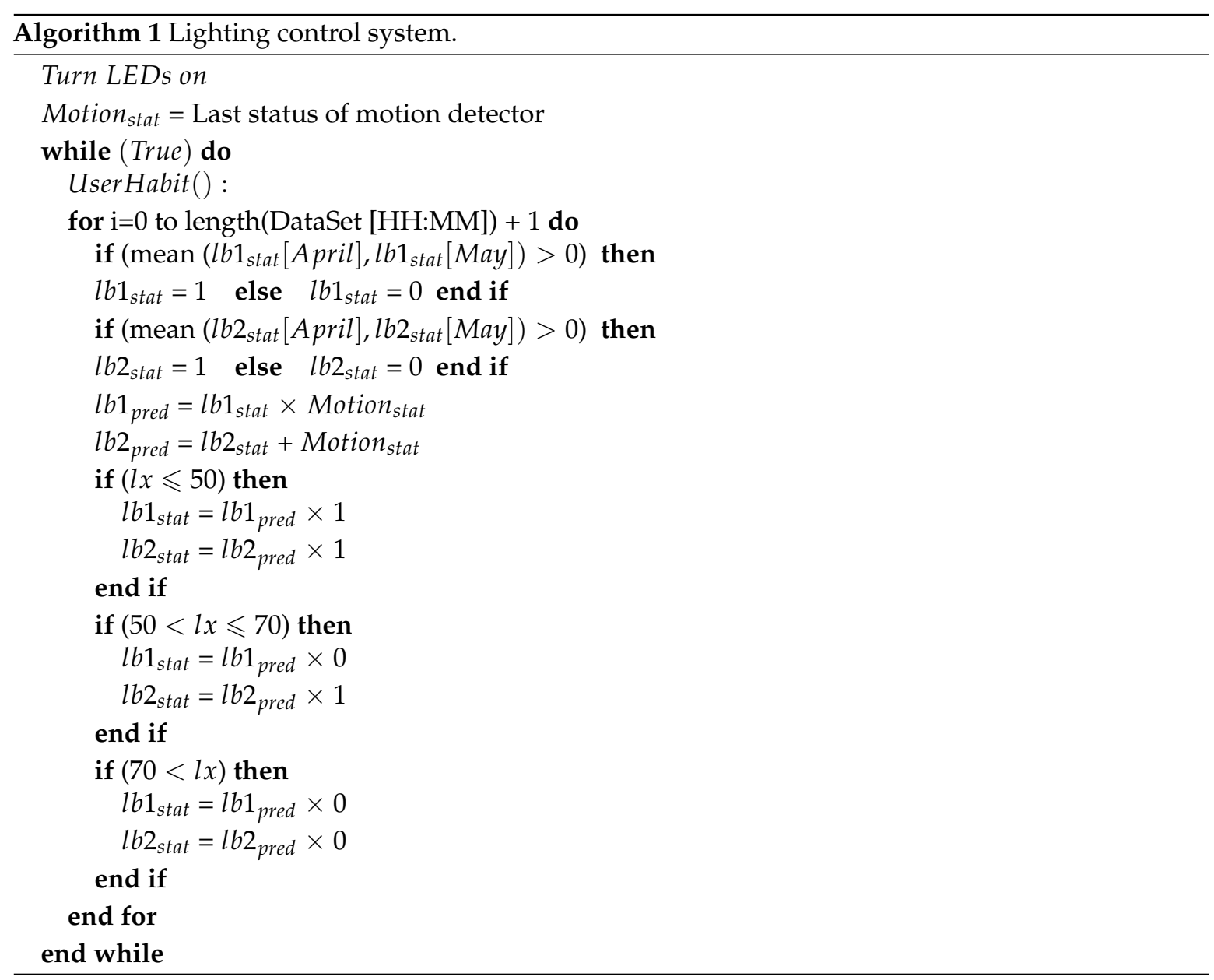

To decide about the status of the next minutes of the LEDs, if they should switch on or off, the Algorithm checks the status of the LEDs for the equal days, hours, and minutes (i.e., [HH:MM]) of the past two months to check if the LED was on or off. Next, using the collected data for April and May, the average status of both LEDs (which can be 1 or 0 ) is calculated. The average status is then multiplied with the status of the motion detector, which can be 1 or 0 . The results of these status are then assigned to the prediction status $l b x_{\text {pred }}$. This step is defined to influence the $\mathcal{H}$ in the energy management strategy. Indeed, the dairy store is not open always and all day long. This is due to several reasons for example closing the store in lunch times or early closings. Using the $l b x_{\text {pred }}$, the Algorithm decides if received ambient illumination is (i) less than 50lx. Then, the Algorithm considers to turn on both of the LEDs or only one of them; (ii) more than 50lx and less than 70l $x$ to turn on only LED1 or none; (iii) more than $70 l x$ to turn off both of the LEDs. 


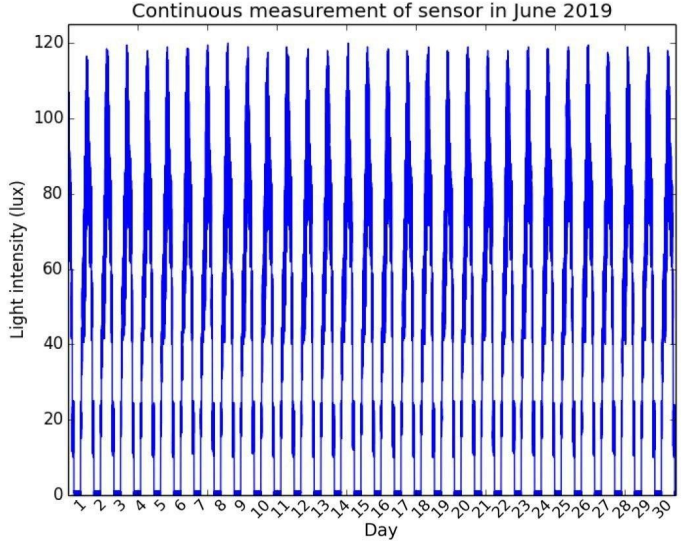

(a) Ambient light measurement in June 2019.

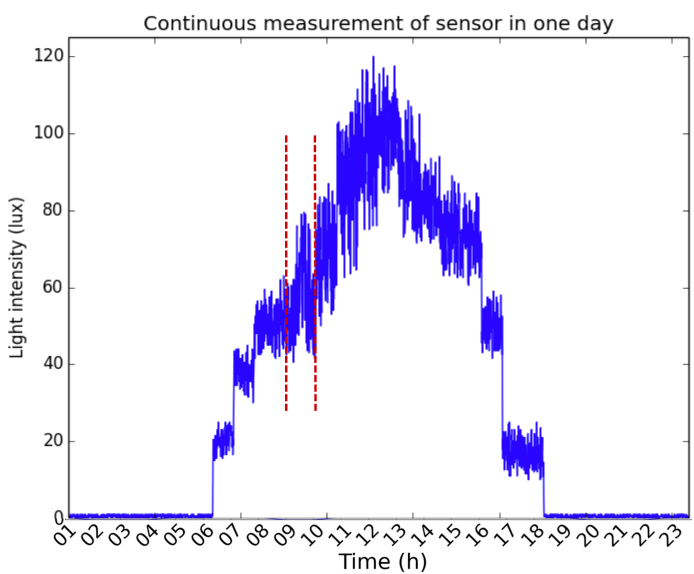

(b) Ambient light measurement on 1st of June 2019.

Figure 8. Ambient light measured by the light sensor.

\section{Results and Analysis}

\subsection{Performance of the IoT-Based Control System}

To evaluate the impact of using IoT-based energy control system on the electricity consumption, we compare the conventional way of using the LEDs (i.e., Lightings 1 and 2) with the IoT-based control mechanism as presented in Algorithm 1. The results are shown in Figure 9. The conventional way refers to the habit of user about using the LEDs which was collected through (UserHabit) as explained in Figure 6-while, in the controlled approach, the amount of light generated by the LEDs depends on ambient light variations measured by the light sensor.

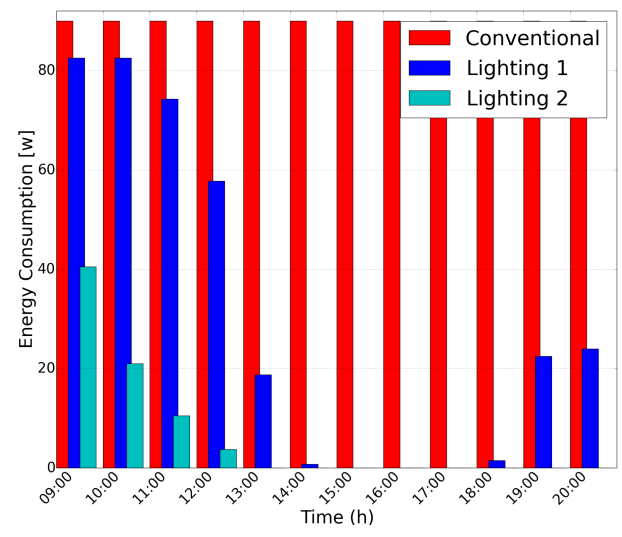

(a) Power consumption on 1st of June 2019.

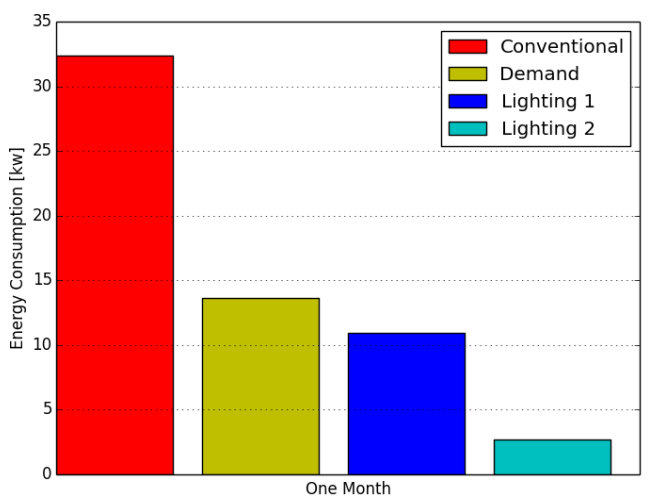

(b) Electricity consumption in June 2019.

Figure 9. Electricity consumption by different LEDs and approaches.

To demonstrate the performance of the IoT-enabled system on reducing the power requirements, first we compare the results of one day of conventional way with the controlled approach. Hence, we use the $\mathcal{H}$ data of 31 May 2019 and compare it with 1 June 2019, while we filter and plot the data from 08:00 a.m. until 8:00 p.m. (Figure 9a). We also illustrate the monthly power requirement of both approached by using the (UserHabit) data for the months May and June 2019 (Figure 9b).

Figure 9a depicts the hourly electricity consumption of the two approached in a varying ambient lighting for each hour $(W / h)$. It can be seen that, in a conventional way, the electricity consumption remains almost constant regardless of light variations. This is while, for the IoT-based approach, 
the electricity consumption drastically decreases with the increase of the received ambient lighting. This result explains that the IoT-based approach is highly dynamic and depends on ambient light fluctuation in the store. The highest values of ambient light were received between 1:00 p.m. and 7:00 p.m., and almost no energy was consumed within this time interval.

In addition, Figure $9 \mathrm{~b}$ shows the monthly electricity consumption by both approaches, while the data filtered from 08:00 a.m. until 8:00 p.m. The demand (yellow bar-chart) which is the summation of the consumption of the LED1 and LED2, in contrast with the conventional approach demonstrates a significant monthly reduction, with almost more than $50 \%$. To conclude, the results shown with these comparisons prove using such an IoT-based control system significantly reduces the electricity consumption and avoids wasting the energy by stopping unnecessary consumption.

\subsection{Renewable Energy Production and Consumption}

The solar panels which are installed at the roof of the building generate $100 \mathrm{Wh}$. To compute the monthly generation, we use the information from the Table 2 and solar panel specification and apply them in the following relation:

$$
\text { Monthly }_{\text {Generation }}=5[\text { panels }] \times 20[w] \times \text { Monthly }_{\text {Average-Sunshine }} \times \text { Days }_{\text {in-Month }}
$$

The monthly energy generation for the year 2019 with the panels are shown in Figure 10 with a blue bar-chart. Comparing these results with the "Demand" shown with a yellow bar-chart in Figure 9b that is equal to $13.64(\mathrm{Kw})$ explains that installing such a green energy generator is not only sufficient for supporting the need of energy requirements of the LED light bulbs used in the dairy store, but there is also extra generation that can be consumed for powering other electric devices or can be sold to the electricity grid. The monthly extra generated energy is also illustrated with light green bar-charts in Figure 10.

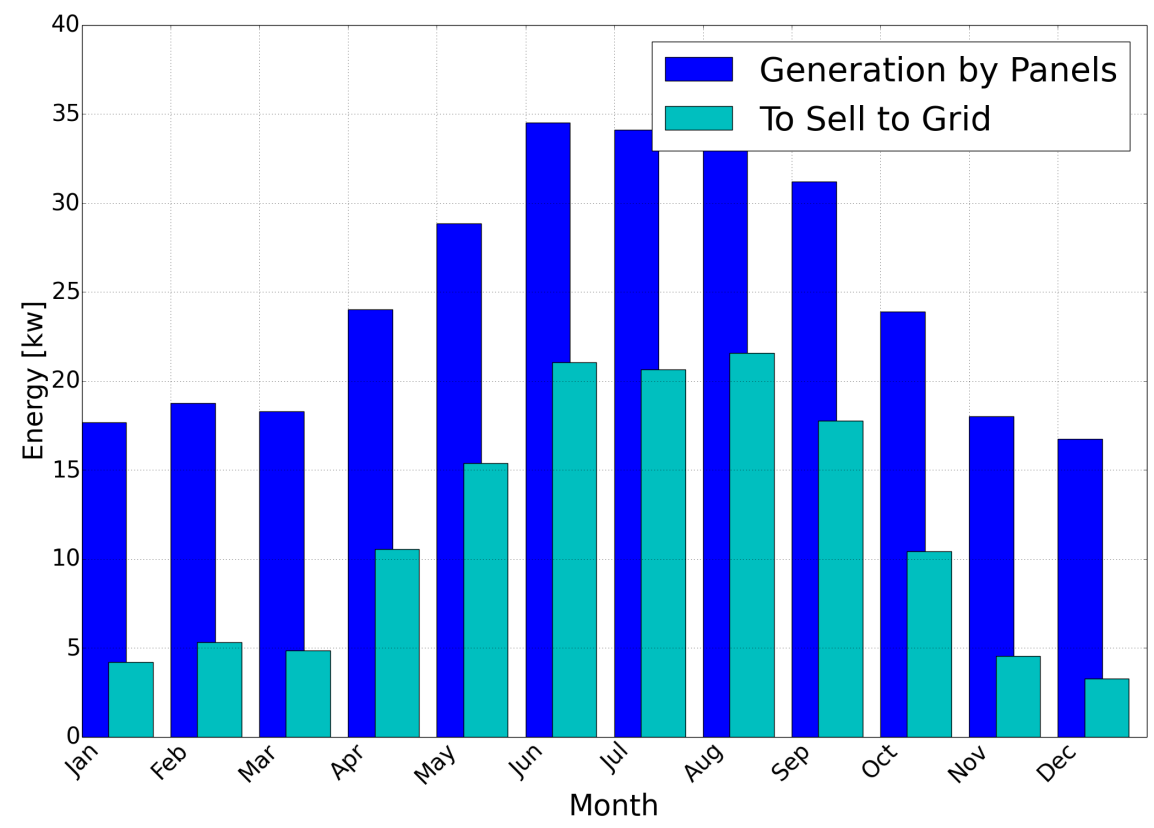

Figure 10. Monthly energy generation in 2019.

\subsection{Environmental and Economic Assessment}

To assess the economic and environmental aspects of applying the solar panels together with the IoT-based energy control system, we investigate the $\mathrm{CO}_{2}$ emission reduction caused using this technology as well as the energy costs. 


\subsection{1. $\mathrm{CO}_{2}$ Emission Reduction}

The grid electricity is mostly supplied from the fossil fuels which causes $\mathrm{CO}_{2}$ emissions [40]. The level of $\mathrm{CO}_{2}$ emissions also depends on the type of utilized fossil fuels. The $\mathrm{CO}_{2}$ emissions by buildings largely contributes to global warming and adds to the air pollution in urban areas [41]. In order to determine the amount of $\mathrm{CO}_{2}$ emission per kilowatt (Emission) for the grid electricity, we multiply the coefficient $(\alpha)$ to the control unit, such that:

$$
\text { Emission }=\alpha \times E_{\text {Conventional }}
$$

where $E_{\text {Conventional }}$ is the conventional way of electricity consumption which is based on user habit and $E_{\text {Demand }}$ denotes to the electricity demand of IoT-based system. The coefficient $(\alpha)$ refers to $\mathrm{CO}_{2}$ emissions from the fossil fuels. According to U.S. electricity generation, $\alpha$ is equal to $0.96 \mathrm{~kg}$ for conventional combined cycle gas turbine plant [42].

Employing the IoT-based control system together with the solar panels contributes to reducing a significant amount of $\mathrm{CO}_{2}$ generation. Indeed, using the data collected from the LEDs in June 2019, and using the information from the Table 2 for the whole year 2019 and applying Equation (5) resulted in an inconsiderable amount of $\mathrm{CO}_{2}$ emission reduction. These results are presented in Table 3.

Table 3. The comparison table for 2019.

\begin{tabular}{ccc}
\hline & June & Whole Year \\
\hline Emission Reductions & $31.1 \mathrm{~kg}$ & $373.25 \mathrm{~kg}$ \\
$C_{s}$ & $3.3 \mathrm{USD} / \mathrm{kw}$ & $235.32 \mathrm{USD} / \mathrm{kw}$ \\
Rev & $1.65 \mathrm{USD} / \mathrm{kw}$ & $10.2 \mathrm{USD} / \mathrm{kw}$ \\
\hline
\end{tabular}

\subsubsection{Cost Evaluation}

Implementing such a system offers two different economic benefits $(B)$ for the user. First, it enables saving costs $\left(C_{S}\right)$ because of the demand management of the system. Second, it provides revenue $(R e v)$ that the owner can get by selling the extra supplied electricity to the grid. Using Net Presenting Value (NPV) of the project can help to understand better the economic-effectiveness of the system. The following formula is used to calculate NPV:

$$
N P V=\sum_{t=1}^{n} \frac{R_{t}}{(1+i)^{t}}
$$

where $R_{t}=$ Netcashinflow - outflows during a single period; and $i$ is the discount rate or return that could be earned in alternative investment; and $t$ refers to the number of timer periods. The initial cost for this project at $t=0$ is 110 USD. Therefore, the total revenue is the sum of saving costs and revenue by exporting the extra electricity to the grid (74 USD per year). According to Iran's renewable energy policy plan, the FiT (feed-in tariffs) for generated solar electricity by residential sector is 0.079 (USD/Kwh).

$$
\begin{gathered}
B=C_{s}+\operatorname{Rev} \\
C_{s}=P \times E_{s} \\
R e v=F i T \times E_{T o G r i d} \\
E_{T o G r i d}=\text { Monthly }{ }_{\text {Generation }}-E_{\text {Demand }}
\end{gathered}
$$

where $P$ is the electricity price and $E_{s}$ is the saved electricity which calculated by ( $E_{\text {Conventional }}-$ $E_{\text {Demand }}$ ). We also consider 0.079 (USD/Kwh) of consumption. For FiT, we also use 0.079 (USD/Kwh) 
based on the price in May 2020. $E_{\text {ToGrid }}$ is the electricity which is sent to the grid and computed by using Equation (4).

Using the data collected in June 2019 from the LEDs and applying the relations above, FiT and the energy price, we observe that our system besides supplying the energy demand of the store offers economic benefits as presented in Table 3. Assuming that the user continues with the same electricity consumption habit for the whole year and assuming the same amount of energy demand; in addition to gaining some revenues, the user saves a considerable amount of money in a year (Table 3).

On the other hand, the yearly operation and maintenance cost is estimated 10 USD. Hence, with assuming 20\% discount rate and for 10 years' time period, the net presenting value of the project after three years is $25 \mathrm{USD}$. As $N P V>0$, this means that the investment would add value to the owner after three years.

\section{Discussion}

The stochastic nature of renewable energy generation resources plays an important role to accurately analyze the results [43]. Indeed, it is mandatory to consider the stochastic nature when planning and operating the renewable energy system. In the planning phase, the stochastic nature of the renewable resource is important to mitigate negative impacts and improve the performance of the system. However, in the operation phase, considering the stochastic nature of renewable energy sources allows us to accurately analyze the performance of the system [44]. For example, when planning a solar system, it is important to place the solar panels in the places which receive direct sunlight and other disturbances such as shadows from buildings and trees are avoided. In addition, the solar panels are protected from heavy rain or snow that may cause failures in operations. In analysis of the operations of the renewable energy system, the ground truth (i.e., reference) data, collected from accurate weather stations can be used to investigate the performance of the system.

In our case, the stochastic nature of renewable energy generation resource (i.e., sunlight) has a direct influence on solar-based electricity generation. In our study, we carried out a continuous experiment in April, May, and June which are among the sunniest months in Tehran. This city is also located in the middle east with a stable sunny and weather situation. Due to these facts, the electricity generation process continued and did not fluctuate to raise a problem during the experiment time. However, to take into account this concern, we have designed an electricity management system for the building which connects to the city electricity grid to receive and send electricity. The designed electricity management system allows for switching from the solar-base power source to the city grid when there is an electricity shortage or when there is a failure in the solar system.

Moreover, to control the lighting system, we have designed an IoT system that measures the ambient light to turn on and off the lights. Our planned IoT system uses three threshold levels of less than 50 lux, between 50 and 70 lux, and more than 70 lux to turn on and off the lights [38]. It is worth recalling that these values were selected to ensure visual comfort for the users. Indeed, the ambient light sometimes is affected by unexpected external sources which may cause errors in light sensor's measurements. For example, a car stopping in front of the store and reflecting the sunlight into the store would result in increasing the light intensity inside the store and exceeding the threshold light levels and therefore turning off the light inadvertently. Therefore, implementing appropriate strategies and intelligent methods to avoid such errors and anomalies is needed.

The anomaly detection methods allow identifying errors in the measurements of sensors in an IoT system. In literature, there are a variety of anomaly detection approaches such as machine learning methods which are used to identify specific failure modes when the received data falls outside of the learnt data model [45]. In an IoT system, applying anomaly detection methods not only enables detecting and correcting errors that improves the sensing performance; but it also provides fault detection and finding malfunctioning sensors which leads to easy maintenance of the system. Moreover, using anomaly detection methods improves security and privacy concerns by detecting for example the denial-of-service attacks and by preserving users data. 


\section{Conclusions}

In this study, we aimed to investigate how the integration of IoT and PV technology can bring added value to the users. Hence, we created a system by integrating PV technology with an IoT system to generate and consume electricity for a lighting use case. We investigated the performance of the system against a conventional way of energy supply and consumption. We also evaluated the environmental and economic impacts of using solar-based electricity generation for such a use case.

We implemented an IoT-based control system which uses the ambient light and combines users' presence with users' historical movement data to control the energy, while five pieces of solar panels were used to generate and supply energy. The control system was used to turn on and off the lights of a dairy store by sensing the ambient daylight received at the store as well as the users' movements inside the place. We also designed an electricity management system that controls the energy generation and supply, and imports and exports electricity to the grid.

The results of our study demonstrated the feasibility of electricity generation from solar systems at smaller sizes and enabling nearly zero-energy buildings. The results of our experiment showed that the use of five PV panels with small sizes as $25 \times 355 \times 510 \mathrm{~mm}$ is not only sufficient to provide the electricity demand of the lighting use case, but the extra generated electricity can be exported to the grid which provides economic benefits for the owners. We also demonstrated the environmental impact of implementing such a system which stops producing huge amounts of $\mathrm{CO}_{2}$. Moreover, our approach motivates the businesses and households in the developing countries with low electricity accessibility, and the countries with solar radiation higher than average and with a high dependency on fossil energies to apply such intelligent systems to supply and consume energy for buildings.

As future work, we plan to create a fully intelligent system by learning the users' habits of using the spaces and defining a full control mechanism for devices and appliances in the space such as fridges and HAVC. Hence, we plan to study the feasibility and employment of solar panels at bigger scales to achieve a fully energy independent and a nearly zero-energy building which we envision to be the future of buildings.

Author Contributions: N.H.M., A.K., and A.A. conceived of the presented idea. A.K. implemented the idea and collected the data. A.A. and N.H.M. supervised the implementation and the experimentation process. A.A., and A.K. prepared the initial version of the paper. N.H.M. revised the structure of the paper and paraphrased the paper. N.H.M. performed visualization and data analytics. A.K. and A.A. provided feedback on the results. A.A. and A.K. also commented on the content and contributed to revisions. All authors discussed the results and contributed to the final manuscript. All authors have read and agreed to the published version of the manuscript.

Funding: This research received no external funding.

Acknowledgments: Open access funding provided by University of Helsinki. This work is supported by Helsinki Center for Data Science (HiDATA) program within Helsinki Institute for Information Technology (HIIT).

Conflicts of Interest: The authors declare no conflict of interest.

\section{References}

1. Oldewurtel, F.; Parisio, A.; Jones, C.N.; Gyalistras, D.; Gwerder, M.; Stauch, V.; Lehmann, B.; Morari, M. Use of model predictive control and weather forecasts for energy efficient building climate control. Energy Build. 2012, 45, 15-27. [CrossRef]

2. Pérez-Lombard, L.; Ortiz, J.; Pout, C. A review on buildings energy consumption information. Energy Build. 2008, 40, 394-398. [CrossRef]

3. Cox, S. Cooling a warming planet: A global air conditioning surge. In Yale Environment 360, Features Section; Yale School of the Environment: New Haven, CT, USA, 2012.

4. Moram, M. Lighting up Lives with Energy Efficient Lighting. 2012. Available online: http://aglobalvillage. org/journal/issue7/waste/lightinguplives / (accessed on 20 February 2020).

5. Nabavi, S.A.; Aslani, A.; Zaidan, M.A.; Zandi, M.; Mohammadi, S.; Hossein Motlagh, N. Machine Learning Modeling for Energy Consumption of Residential and Commercial Sectors. Energies 2020, 13, 5171. [CrossRef] 
6. Motlagh, N.H.; Mohammadrezaei, M.; Hunt, J.; Zakeri, B. Internet of Things (IoT) and the Energy Sector. Energies 2020, 13, 494. [CrossRef]

7. Al-Ali, A.R.; Zualkernan, I.A.; Rashid, M.; Gupta, R.; AliKarar, M. A smart home energy management system using IoT and big data analytics approach. IEEE Trans. Consum. Electron. 2017, 63, 426-434. [CrossRef]

8. Gad, Y.; Diab, H.; Abdelsalam, M.; Galal, Y. Smart Energy Management System of Environmentally Friendly Microgrid Based on Grasshopper Optimization Technique. Energies 2020, 13, 5000. [CrossRef]

9. Zhao, H.X.; Magoulès, F. A review on the prediction of building energy consumption. Renew. Sustain. Energy Rev. 2012, 16, 3586-3592. [CrossRef]

10. Ghaffarianhoseini, A.; AlWaer, H.; Ghaffarianhoseini, A.; Clements-Croome, D.; Berardi, U.; Raahemifar, K.; Tookey, J. Intelligent or smart cities and buildings: A critical exposition and a way forward. Intell. Build. Int. 2018, 10, 122-129. [CrossRef]

11. Bedi, G.; Venayagamoorthy, G.K.; Singh, R.; Brooks, R.R.; Wang, K.C. Review of Internet of Things (IoT) in electric power and energy systems. IEEE Internet Things J. 2018, 5, 847-870. [CrossRef]

12. Metallidou, C.K.; Psannis, K.E.; Egyptiadou, E.A. Energy Efficiency in Smart Buildings: IoT Approaches. IEEE Access 2020, 8, 63679-63699. [CrossRef]

13. European Commission. Energy Efficient Buildings: Nearly Zero-Energy Buildings (NZEB). 2020. Available online: https:/ / ec.europa.eu/energy/content/nzeb-24_en (accessed on 5 November 2020).

14. Guravaiah, K.; Velusamy, R.L. Prototype of home monitoring device using Internet of Things and river formation dynamics-based multi-hop routing protocol (RFDHM). IEEE Trans. Consum. Electron. 2019, 65, 329-338. [CrossRef]

15. Lund, H.; Andersen, A.N.; Østergaard, P.A.; Mathiesen, B.V.; Connolly, D. From electricity smart grids to smart energy systems - A market operation based approach and understanding. Energy 2012, 42, 96-102. [CrossRef]

16. Motlagh, N.H.; Khajavi, S.H.; Jaribion, A.; Holmstrom, J. An IoT-based automation system for older homes: A use case for lighting system. In Proceedings of the 2018 IEEE 11th Conference on Service-Oriented Computing and Applications (SOCA), Paris, France, 20-22 November 2018; pp. 1-6. [CrossRef]

17. Yamauchi, M.; Ohsita, Y.; Murata, M.; Ueda, K.; Kato, Y. Anomaly Detection in Smart Home Operation From User Behaviors and Home Conditions. IEEE Trans. Consum. Electron. 2020, 66, 183-192. [CrossRef]

18. Kim, S.; Park, M.; Lee, S.; Kim, J. Smart Home Forensics-Data Analysis of IoT Devices. Electronics 2020, 9, 1215. [CrossRef]

19. Chen, H.; Chou, P.; Duri, S.; Lei, H.; Reason, J. The Design and Implementation of a Smart Building Control System. In Proceedings of the 2009 IEEE International Conference on e-Business Engineering, Macau, China, 21-23 October 2009; pp. 255-262.

20. Jeong, Y.; Joo, H.; Hong, G.; Shin, D.; Lee, S. AVIoT: Web-based interactive authoring and visualization of indoor internet of things. IEEE Trans. Consum. Electron. 2015, 61, 295-301. [CrossRef]

21. Sun, Y.; Wu, T.; Zhao, G.; Guizani, M. Efficient Rule Engine for Smart Building Systems. IEEE Trans. Comput. 2015, 64, 1658-1669. [CrossRef]

22. King, J.; Perry, C. Smart Buildings: Using Smart Technology to Save Energy in Existing Buildings. 2017. Available online: https://www.aceee.org/research-report/a1701 (accessed on 8 October 2020).

23. McCann, R.; Le, A.T.; Traore, D. Stochastic Sliding Mode Arbitration for Energy Management in Smart Building Systems. In Proceedings of the 2008 IEEE Industry Applications Society Annual Meeting, Edmonton, AB, Canada, 5-9 October 2008; pp. 1-4.

24. Zou, H.; Zhou, Y.; Yang, J.; Spanos, C.J. Towards occupant activity driven smart buildings via WiFi-enabled IoT devices and deep learning. Energy Build. 2018, 177, 12-22. [CrossRef]

25. Shaikh, P.H.; Nor, N.B.M.; Nallagownden, P.; Elamvazuthi, I.; Ibrahim, T. A review on optimized control systems for building energy and comfort management of smart sustainable buildings. Renew. Sustain. Energy Rev. 2014, 34, 409-429. [CrossRef]

26. Turgut, Z.; Aydin, G.Z.G.; Sertbas, A. Indoor Localization Techniques for Smart Building Environment. Procedia Comput. Sci. 2016, 83, 1176-1181. [CrossRef]

27. Bradfield, K.; Allen, C. User Perceptions of and Needs for Smart Home Technology in South Africa. In Advances in Informatics and Computing in Civil and Construction Engineering; Mutis, I., Hartmann, T., Eds.; Springer International Publishing: Cham, Switzerland, 2019; pp. 255-262. 
28. Lee, I.; Lee, K. The Internet of Things (IoT): Applications, investments, and challenges for enterprises. Bus. Horizons 2015, 58, 431-440. [CrossRef]

29. AlFaris, F.; Juaidi, A.; Manzano-Agugliaro, F. Intelligent homes' technologies to optimize the energy performance for the net zero energy home. Energy Build. 2017, 153, 262-274. [CrossRef]

30. Gray, C.; Ayre, R.; Hinton, K.; Campbell, L. 'Smart' Is Not Free: Energy Consumption of Consumer Home Automation Systems. IEEE Trans. Consum. Electron. 2019, 66, 87-95. [CrossRef]

31. Lohr, C.; Kerdreux, J. Improvements of the xAAL Home Automation System. Future Internet 2020, $12,104$. [CrossRef]

32. Oh, E.; Son, S.Y. A framework for consumer electronics as a service (CEaaS): A case of clustered energy storage systems. IEEE Trans. Consum. Electron. 2017, 63, 162-168. [CrossRef]

33. Kumar, N.M.; Atluri, K.; Palaparthi, S. Internet of Things (IoT) in Photovoltaic Systems. In Proceedings of the 2018 National Power Engineering Conference (NPEC), Madurai, India, 9-10 March 2018; pp. 1-4.

34. Aslani, A.; Naaranoja, M.; Zakeri, B. The prime criteria for private sector participation in renewable energy investment in the Middle East (case study: Iran). Renew. Sustain. Energy Rev. 2012, 16, 1977-1987. [CrossRef]

35. Motlagh, N.H.; Zaidan, M.A.; Lagerspetz, E.; Varjonen, S.; Toivonen, J.; Mineraud, J.; Rebeiro-Hargrave, A.; Siekkinen, M.; Hussein, T.; Nurmi, P.; et al. Indoor air quality monitoring using infrastructure-based motion detectors. In Proceedings of the 2019 IEEE 17th International Conference on Industrial Informatics (INDIN), Helsinki, Finland, 22-25 July 2019; Volume 1, pp. 902-907.

36. Ghasemzadeh, H.; Maerefat, M.; Azimi, A. Design of a combined cooling, heating and power system for a five-storey residential building in the hot climate of iran. In Proceedings of the SEBUA-12 ICHMT International Symposium on Sustainable Energy in Buildings and Urban Areas, Kusadasi, Turkey, 14-20 July 2012.

37. Weather Atlas. Tehran, Iran—Detailed Climate Information and Monthly Weather Forecast. Available online: https:/ / www.weather-atlas.com/en/iran/tehran-climate (accessed on 22 April 2020).

38. Sharp, T.R. Derivation of Building Energy Use Intensity Targets for ASHRAE Standard 100; Technical Report; Oak Ridge National Lab. (ORNL): Oak Ridge, TN, USA, 2014.

39. Zaidan, M.A.; Motlagh, N.H.; Fung, P.L.; Lu, D.; Timonen, H.; Kuula, J.; Niemi, J.V.; Tarkoma, S.; Petäjä, T.; Kulmala, M.; et al. Intelligent calibration and virtual sensing for integrated low-cost air quality sensors. IEEE Sensors J. 2020, 20, 13638-13652. [CrossRef]

40. Atilgan, B.; Azapagic, A. Life cycle environmental impacts of electricity from fossil fuels in Turkey. J. Clean. Prod. 2015, 106, 555-564. [CrossRef]

41. Motlagh, N.H.; Lagerspetz, E.; Nurmi, P.; Li, X.; Varjonen, S.; Mineraud, J.; Siekkinen, M.; Rebeiro-Hargrave, A.; Hussein, T.; Petaja, T.; et al. Toward massive scale air quality monitoring. IEEE Commun. Mag. 2020, 58, 54-59. [CrossRef]

42. U.S. Energy Information Administration. How Much Carbon Dioxide Is Produced Per Kilowatthour of U.S. Electricity Generation? 2020. Available online: https:/ /www.eia.gov/tools/faqs / faq.php?id=74\&t=11 (accessed on 20 February 2020).

43. Talari, S.; Shafie-Khah, M.; Osório, G.J.; Aghaei, J.; Catalão, J.P. Stochastic modelling of renewable energy sources from operators' point-of-view: A survey. Renew. Sustain. Energy Rev. 2018, 81, 1953-1965. [CrossRef]

44. Zakaria, A.; Ismail, F.B.; Lipu, M.H.; Hannan, M.A. Uncertainty models for stochastic optimization in renewable energy applications. Renew. Energy 2020, 145, 1543-1571. [CrossRef]

45. Cook, A. A.; Misırlı, G.; Fan, Z. Anomaly Detection for IoT Time-Series Data: A Survey. IEEE Int. Things J. 2019, 7, 6481-6494. [CrossRef]

Publisher's Note: MDPI stays neutral with regard to jurisdictional claims in published maps and institutional affiliations.

(C) 2020 by the authors. Licensee MDPI, Basel, Switzerland. This article is an open access article distributed under the terms and conditions of the Creative Commons Attribution (CC BY) license (http://creativecommons.org/licenses/by/4.0/). 